\title{
Cylotogical Postmortem Changes in Highly Specialized Cells Subjected to Different Causes of Necrosis
}

\author{
V. B. Meyer-Rochow ${ }^{1}$ and M. Järvilehto ${ }^{2}$ \\ ${ }^{1}$ Institute of Arctic Medicine, University of Oulu, Aapistie 1, SF-90220 Oulu, Finland \\ ${ }^{2}$ Department of Biology/Animal Physiology, University of Oulu, P.O. Box 335, \\ SF-90570 Oulu, Finland
}

Accepted June 30, 1997

Emphasis in cytological research has traditionally been on representing and understanding cells and their processes in the living state; changes occurring in the cell after death were considered unphysiological and uninteresting. Yet, with the attention programmed cell deaths have received lately (Duke et al. 1996, Fraser et al. 1996, Korsmeyer 1995, Martikainen 1996), there comes a need to know more about accidental cell death as well.

It could be argued that if programmed cell deaths, until very recently clumped together under the term "apoptotic", do not constitute a homogeneous category, but may be classified on the basis of highly diagnostic ultrastructural images as a) apoptosis, b) atrophy, and c) differentiation (Bowen et al. 1996), then accidental cell deaths may also fall into a variety of categories. Unfortunately, the prevailing view is still that accidental cell deaths collectively conform to a single form of 'necrosis'. The latter is thought to pass along the following regular chain of events: calcium overload with subsequent cell oedema, dilation of endoplasmic reticulum, polysome disintegration, and mitochondrial swelling (Bowen et al. 1996).

When we noticed that in rabbit photoreceptors postmortem changes affecting visual and glial cells were most dramatic within the first two hours following death (Pow and Crook 1994), but the time-course for dying visual cells in the fly eye was different (Meyer-Rochow et al. 1996), we decided to take a closer look at whether necrotic photoreceptor cell deaths really were uniform in their ultrastructural manifestations, given different causes for their demise.

The choice of the experimental cell type fell on the fly photoreceptor cell, firstly because a great deal is known about the ultrastructural organization of normal, healthy fly eyes and secondly because for studies on photoreceptor dystrophies and programmed cell deaths the eye of the fruitfly Drosophila had previously been used as a model (Stark et al. 1995). Furthermore, since studies on visual parameters are often based on results obtained from eyes of isolated fly-heads, even many hours after decapitation, it seemed useful to know to what extent the ultrastructures of such eyes differed from those that were fixed immediately.

\section{Material and methods}

Four groups of 10 apparently healthy and similarly-aged individuals of the fly Calliphora erythrocephala (irrespective of sex) during the day in light were subjected to: 1. decapitation, 2. ethyl-ether, 3. gaseous $\mathrm{CO}_{2}$, and 4. $\mathrm{KCN}$-vapour. Following these 'regimens', 15 and 30 min as well as 3, 6, and $24 \mathrm{hr}$ later after illuminated storage in covered Petri dishes (to keep humidity constant in the case of the isolated heads), fly eyes were prepared for electron microscopic examinations in the usual way, i.e. prefixation with phosphate-buffered ( $\mathrm{pH} \mathrm{7.4)} \mathrm{glutaralde-}$ hyde-paraformaldehyde, fixation in $1 \%$-buffered $\mathrm{OsO}_{4}$, dehydration, and embedding in resin.

In order to compare the ultrastructures of the photoreceptor cells from the four groups, 
care was taken that only sections through identical areas of the eyes were chosen. Furthermore, since photoreceptive membranes (as the major sites of the photopigment molecules) and mitochondria (as the major suppliers of energy) hold key-positions in the functional viability of the photoreceptor cell, these structures in particular were made the subjects of the comparative analysis of postmortem ultrastructural changes. All observations were carried out under a Jeol JEM 100 CX-II transmission electron microscope in the Department of Electron Microscopy of Oulu University.

\section{Results}

The main emphasis in this comparative study was placed on (a) rhabdomeres with their microvilli as places for photopigment and phototransduction and (b) mitochondria as organelles mirroring metabolic activity. At this stage of the investigation, a qualitative assessment of noteworthy changes, accompanied by representative electron micrographs, seemed most appropriate to us.

Within the first $30 \mathrm{~min}$ following 'death', photoreceptors from the decapitated flies could be considered normal (Fig. 1), when sections were examined under the electron microscope at magnifications of $3600,10,000$, and 19,000. Each rhabdomere of the photoreceptors displayed neatly arranged and uniformly large subrhabdomeric vesicles, microtubules were visible in the photoreceptor cytoplasm, mitochondria showed the usual cristae and regular dimensions, and central filaments were clearly discernible in transversely-sectioned rhabdom microvilli.

In ether-treated animals $30 \mathrm{~min}$ postmortem changes included the disappearance of the subrhabdomeric vesicles, the almost total loss of microtubules, an absence of microvillar central filaments, and washed-out pigment grains. Cell boundaries as well as mitochondria remained clearly identifiable, but the latter had swollen to about twice their normal size and cristae often appeared loose and torn (Fig. 2).

In $\mathrm{CO}_{2}$-treated material $30 \mathrm{~min}$ postmortem subrhabdomeric vesicles appeared enlarged and in a process of drifting proximally (towards the cell centre) away from the edge of the rhabdom. The microvillar central dense core filaments were well preserved and, although affected, the system of microtubules was still present. Mitochondria appeared slightly swollen and the cristae displayed less regular parallel alignments than under normal conditions.

Thirty minutes following an exposure to $\mathrm{KCN}$-vapour subrhabdomeric vesicles were less numerous than in the corresponding $\mathrm{CO}_{2}$ material. The mitochondrial dimensions were almost normal and cristae were present, but appeared somewhat denser than under normal conditions. Some disruptions of the microvillar dense core filament and the microtubular system were observed, but the changes were minor (Fig. 3).

Three to six hours after decapitation rhabdomeres (Fig. 4) lost their clear delineations with the cytoplasm, showing increasingly closer fusion with and distance to their respective photoreceptor cell bodies (rather than being positioned somewhat like peninsulas projecting outward from the photoreceptor cell into the intercellular space). Mitochondria were enlarged and showed cristae lined with minute electron opaque particles, possibly ribosomes. The microtubular system was gone, but the central dense core filaments within the rhabdom microvilli were still mostly visible in transversely sectioned material. Clear cytoplasmic vesicles

Figs. 1-7. 1. Edge of retinula cell with rhabdomere (R) $15 \mathrm{~min}$ after decapitation in air. 2. A similar region with rhabdomere $(R)$ in cell exposed to gaseous ethylether for $30 \mathrm{~min}$. 3 . Edge of retinula cell and rhabdomere $(R)$ of cell exposed to $\mathrm{KCN}$-vapour for $5 \mathrm{~min}$. 4. Situation of rhabdomere $(R) 6 \mathrm{hr}$ following decapitation in air. 5. Situation of rhabdomere (R) after $5 \mathrm{hr}$ exposure to gaseous ethylether. 6. Situation of rhabdomere (R) after $6 \mathrm{hr}$ exposure to $\mathrm{CO}_{2}$-gas.

7. Situation of rhabdomere (R) after $3.5 \mathrm{hr}$ exposure to $\mathrm{KCN}$-vapour. Bar: $1 \mu \mathrm{m}$. 

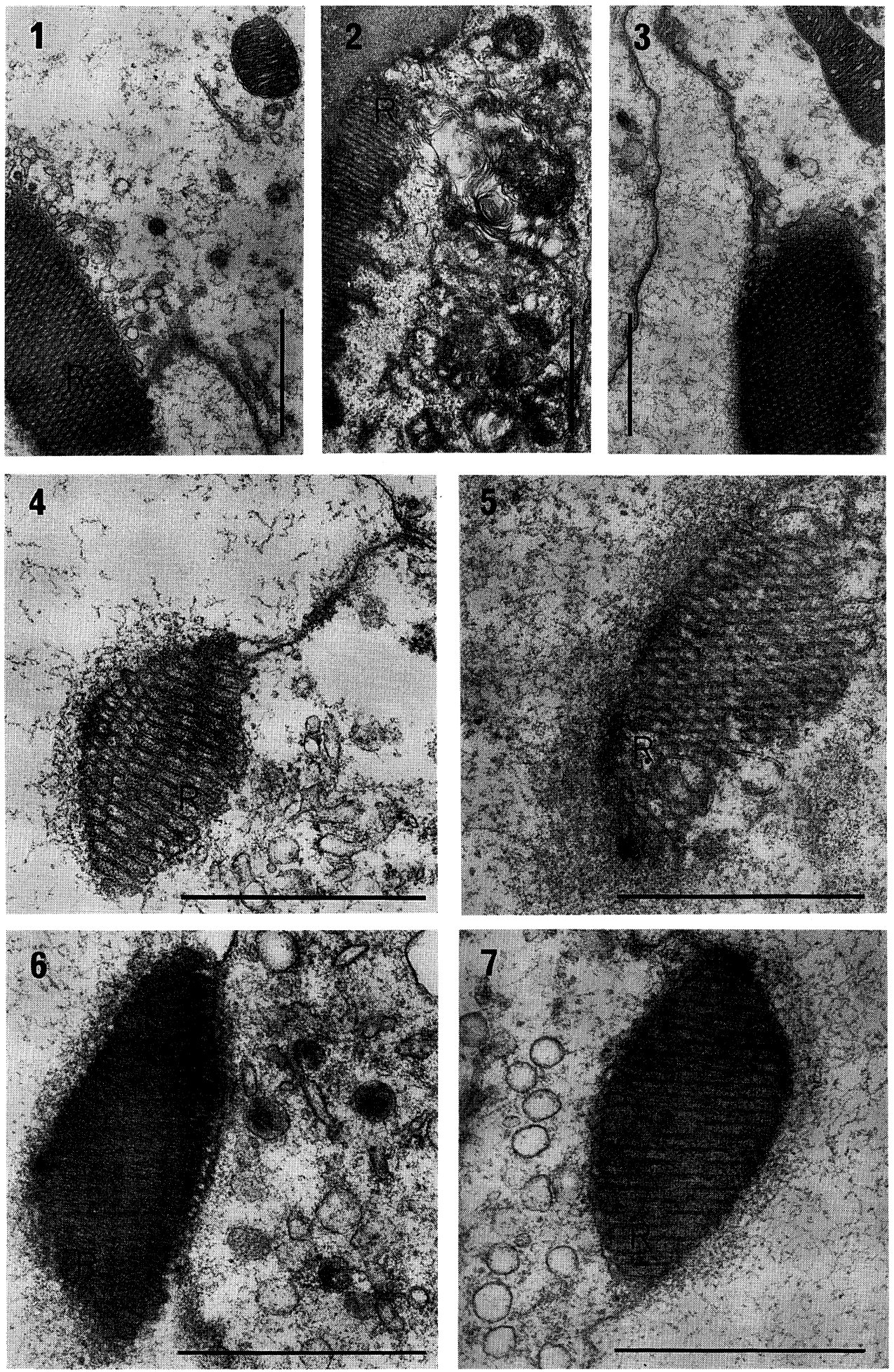

Figs. 1-7. 

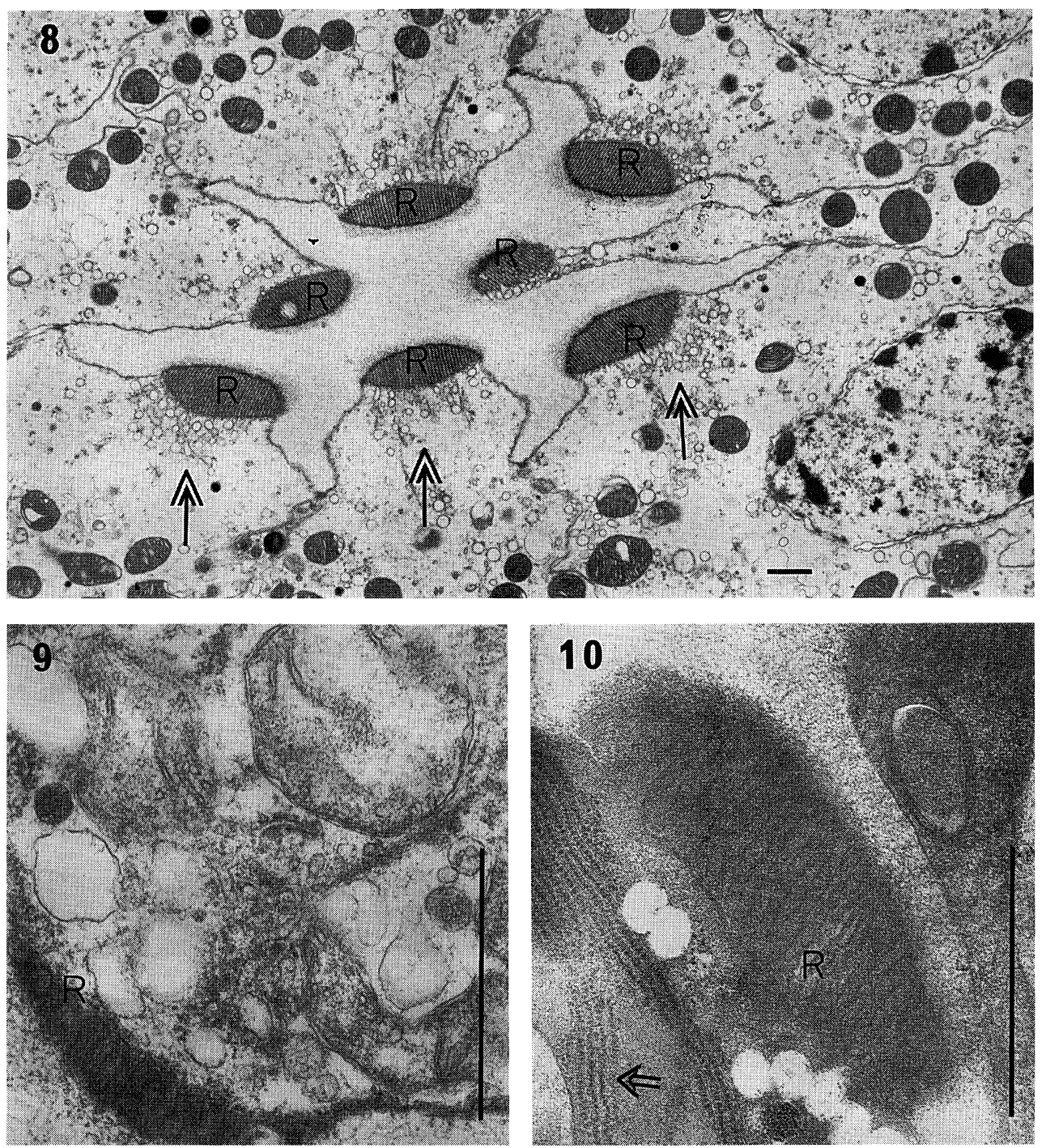

Figs. 8-10. 8. Low power electron micrograph, showing vesicle formation (arrows) at the edge of the rhabdomeres (R) in material exposed for $3.5 \mathrm{hr}$ to $\mathrm{KCN}$-vapour. 9. Rhabdomeredisintegration $(R)$ in material decapitated in air $24 \mathrm{hr}$ postmortem. 10. Rhabdomere-disintegration ( $R$ ) and endoplasmic reticulum formations (arrow) in material exposed to $\mathrm{CO}_{2}$-gas for $24 \mathrm{hr}$. Bar: $1 \mu \mathrm{m}$.

became more conspicuous.

A three to six hours exposure to ether left photoreceptor cells with broken and ruptured membranes, allowing extra- and intracellular contents to mix (Fig. 5). Rhabdomeres displayed breakages of microvilli, but never along the edge with their corresponding retinula cytoplasm. Mitochondria and their cristae were destroyed.

In $\mathrm{CO}_{2}$-treated animals 3-6 hr postmortem changes (Fig. 6) included an apparent separation (or 'heightened' demarcation) of rhabdomeres from their corresponding cytoplasms. Mitochondria were enlarged, but as with the corresponding material from decapitated flies, contained apparently normal cristae lined with granular, electron opaque material. The development of some intracellular cisternae and rows of endoplasmic reticulum in the photoreceptor cell cytoplasm are indicative of some active processes. Desmosomes between neighbour- 
ing cells seemed affected and the dense core filaments in the rhabdom microvilli were no longer identifiable.

In the $\mathrm{KCN}$-animals 3-6 hr postmortem rhabdomere delineations to both extracellular space and corresponding intracellular cytoplasms were still very obvious (Fig. 7). Large numbers of vesicles were very conspicuous along the intracellular edge of the rhabdomere and apparently in the process of moving along some remnant microtubules towards more central regions of the cytoplasm (Fig. 8). Mitochondria were noticeably swollen, but still endowed with parallel cristae. Transversely-sectioned rhabdoms continued to reveal traces of the central microvillar dense core filaments.

After $24 \mathrm{hr}$ (Fig. 9) rhabdoms were much reduced in size; there was little coherence between microvilli, desmosomes were gone, mitochondria enormously swollen, cristae present but disrupted, and ribosomes and/or glycogen granules abundant in localized places of the bodies of the photoreceptor cells of the decapitated animals.

In ether-treated animals all membranes and intracellular organelles had dissolved and apart from foggy shades of grey covering the section to varying degrees, no details were discernible.

In $\mathrm{CO}_{2}$-treated animals, eyes examined $24 \mathrm{hr}$ later (Fig. 10) displayed swollen rhabdomeres with pigment or otherwise electron opaque grains having taken up positions close to the cytoplasmic (i.e. inner) edges of the rhabdomeres. Large strings of endoplasmic reticulum (rather similar to those found in senescent cells of the bee Melipona: DaCruz-Landim and Morelli-Silva de Moraes 1973) were apparent while the swollen mitochondria contained much looser and frequently highly disrupted cristae.

\section{Discussion}

Decapitating flies in air or keeping whole flies in $\mathrm{CO}_{2}$-filled chambers both lead to necrosis through anoxia. However, the progression of cell death as seen by the ultrastructural images of cytoplasmic vesicles, subrhabdomeric cisternae, endoplasmic reticulum, and mitochondria is clearly not identical in the two situations, let alone the other experimental conditions. The only unifying character seems that cell deaths proceed from the periphery toward the centre, affecting the rhabdomeres last.

While $\mathrm{KCN}$ is undoubtedly a potent cell poison, a total arrest of all intracellular activities did not take place immediately after application. In fact, signs of metabolic activity and certain aspects of intracellular viability were still present in the fly photoreceptor cell several hours after the exposure to KCN. Ethyl ether with its lipid-dissolving capacity caused a very different scenario of necrotic events and presumably led to cell death primarily not because of anoxia, but membrane instability and leakage.

The different reactions of the subrhabdomeric vesicles is of interest in view of the fact that they are thought to store $\mathrm{Ca}^{2+}$ and are crucial to the phototransduction process (Minke and Selinger 1996). Their initial diminution and rapid disapearance in ether and $\mathrm{KCN}$-treated flies is irreconcilable with any possible postmortem continuation of photoreception. Their distinct presence in decapitated and even $\mathrm{CO}_{2}$-material, however, suggests that at least this structural feature, apart from an increse due to swelling, remained relatively unaffected into the postmortem period. The eventual 'pinching off' of the rhabdomere from its cytoplasmic connection in $\mathrm{CO}_{2-}$ and $\mathrm{KCN}$-treated material might represent a last attempt of the cell to shed its energetically most costly component, namely the assembly of photoreceptive membranes (Tsacopoulos 1995).

The observed loosening of the mitochondrial ultrastructure, an accumulation of coated vesicles and ER in the cytoplasm, the expansion of the system of cisternae, and the loss of microtubules and other cytoskeletal elements, are features shared with visual cells under severe 
photo-induced stress (Meyer-Rochow and Horridge 1975, Eguchi and Meyer-Rochow 1983). This similarity is not really surprising, since exposure to light can kill cells (Meyer-Rochow and Tiang 1984).

In conclusion, what the results demonstrate is firstly, that certain aspects of photoreceptor cell function can be 'dissected' by using a range of lethal treatments and that secondly, death by necrosis is not as uniform a process as was generally assumed, but depends on the nature and causes of the accidental death. Consequently, as with the programmed cell deaths, for which Bowen et al. (1996) have recently established three subgroups, accidental cell deaths also require the recognition of different subcategories. How many there are and what diagnostic characters are to be used to differentiate them remains to be elucidated and may, in fact, vary from tissue to tissue.

\section{Summary}

Cells die either accidental or physiologically programmed deaths. Our results based on ultrastructural changes observed in fly photoreceptors 15 and $30 \mathrm{~min}, 3,6$ and $24 \mathrm{hr}$ postmortem, demonstrate that death by necrosis is not as uniform a process as had generally been assumed, but depends on the nature and specific causes of the accidental cell demise, which appears to begin peripherally and then moves inward. Consequently, as with programmed cell deaths, death by necrosis also requires the recognition of different sub-categories.

\section{Acknowledgement}

We wish to thank the Finnish Academy for the support of this project and Mrs. Riita Harjula for her skillful and competent assistance.

\section{References}

Bowen, I. D., Mullarkey, K. and Morgan, S. M. 1996. Programmed cell death during metamorphosis in the blow-fly Calliphora vomitoria. Microsc. Res. Tech. 34: 202-217.

DaCruz-Landim, C. and Morelli-Silva de Moraes, R. L. 1973. Degenerative structures in the hypopharyngeal gland from ageing bees (Melipona quadrifasciata anthidioides). Revista de Biologia 9: 157-168.

Duke, R. C., Ojcius, D. M. and Young, J. D. 1996. Cell suicide in health and disease. Sci. Am. 96: 48-55.

Eguchi, E. and Meyer-Rochow, V. B. 1983. Trophospongium-like structures in an insect eye: response of retinula cells of Papilio xuthus (Lepidoptera) to irradiation with uv-light. Cell Tiss. Res. 231: 519-526.

Fraser, A., McCarthy, N. and Evan, I. G. 1996. Biochemistry of cell death. Curr. Opinion Neurobiol. 6: 71-80.

Korsmeyer, S. J. 1995. Regulators of cell death. Trends in Genetics 11: 101-105.

Martikainen, P. 1996. Apoptoosi-solun elämän ja kuoleman kysymys. Solubiol. 14: 15-19.

Meyer-Rochow, V. B. and Horridge, G. A. 1975. The eye of Anoplognathus. Proc. Roy. Soc. Lond. B 188: 1-30.

— and Tiang, K. M. 1984. The eye of Jasus edwardsii-electrophysiology, histology, and visual behaviour. Zoologica 45: 1-85.

-, Harjula, R. and Järvilehto, M. 1996. Cell death under the electron microscope-ultrastructural details of dying photoreceotprs. Acta Univ. Oulu. 286: 149-153.

Minke, B. and Selinger, Z. 1996. The role of trp and calcium in regulating photoreceptor function in Drosophila. Current Opin. Neurobiol. 6: 459-466.

Pow, D. V. and Crook, D. K. 1994. Rapid postmortem changes in the cellular localisation of aminoacid transmitters in the retina as assessed by immunocytochemistry. Brain Res. 653: 199-209.

Stark, W. S., Hunnius, D., Mertz, J. and Chen, D-M. 1995. Drosophila as a model for photoreceptor dystrophies and cell death. In: Anderson, R. E. (ed.) Degenerative diseases of the retina. Plenum Press, New York, pp. 217226.

Tsacopoulos, M. 1995. Metabolite exchanges and signal trafficking between glial cells and photoreceptor neurons in the honeybee retina. Verh. Dtsch. Zool. Ges. 88: 53-59. 